\title{
PREDICTING THE DIRECTION OF SELEGTIVE MEMORY FROM PERSONALITY VARIABLES
}

\author{
TSUNEO YAMASHITA ${ }^{1}$
}

Tokyo University of Education

\begin{abstract}
The present study was designed to clarify the relationship between selective memory and personality variables especially related to self-concept. The direction of selective memory was measured by the ratio of the amount of recall of the self-consistent verbal stimuli to that of self-inconsistent stimuli in paired associate learning. This ratio was assumed to be a dependent variable in the present study. Independent variables which were related to personality variables were (1) Self-Ideal Discrepancy; (2) Self-Esteem; (3) Time Orientation; (4) MMPI, and so on. These variables were measured respectively for sixty undergraduate students. Obtained data were analyzed by the multiple regression model. The degree of predictability and the contribution of each personality variables to the dependent variable were computed.
\end{abstract}

The problem of subjective factors in memory has long been investigated by a number of researchers. The well known doctrine of the relation of hedonic tone to memory revival provided by Freud and the goal tension theory developed by Lewin have played the important roles in those studies.

Restricting the topic only to the studies using verbal stimuli as memory material, still numerous studies were carried out in the 1930's. The majority of them were based on Freud's theory of repression. Sharp (1938), for example, designed an experimental test of Freud's doctrine. He found (1) that unpleasant verbal stimuli were less likely to be revived than pleasant and neutral ones, and (2) that pleasant verbal stimuli were more likely to be revived than unpleasant and neutral ones.

These studies were followed by research scientists who applied more exact empirical methods and developed a new

${ }^{1}$ With grateful acknowledgment to Prof. S. Nagashima, Dr. K. Harano of Tokyo University of Education, and Mr. K. Mizuno of Institute of Behavioral Sciences, for their valuable suggestions and criticisms. Thanks are due to Mrs. G.T. Hatch who helped me with the translation of the manuscript of this paper. language for the understanding of defensive phenomena. In place of somewhat mentalistic psychoanalytic terminology, behavioral process such as selective recall or selective learning came to be stressed as explanation for the data (Goidin, 1964).

There are a few studies discussing the relationship of self-consistency to selective memory. One of these was carried out by Cartwright (1956). He rejected in his experiment two null hypotheses suggested by Rogers' proposition (1951). The first null hypothesis was that there would be no difference in immediate recall performance between self-consistent and selfinconsistent stimuli. The second one was that the difference in recall performance between consistent and inconsistent stimuli would be the same for adjusted and maladjusted groups.

The present author raised the problem as regards Cartwright's findings that selfconsistent verbal stimuli were easily revived by both adjusted and maladjusted person and that especially in case of maladjusted person, consistent stimuli tended to be much more easily revived than inconsistent stimuli. There would be individual difference among maladjusted persons. 
Gordon (1959) classified the maladjusted persons into two personality types, i.e., sensitizer and represser and the studies conducted by Gossett (1964) and McReynolds \& Ullman (1964) which adopted Gordon's types seemed to suggest that there would be difference between them.

Repressers are defined as those who tend to use avoidance, denial, and repression of potential threat and conflict as a primary mode of adjustment. Sensitizers are defined as those who are alerted to and perhaps overinterpret potential threat and conflict and who use intellectual and obsessive defenses as a primary mode of adjustment (Altrocchi et al., 1960).

These studies mentioned above led the present author to expect that, in learning experiment, some persons would tend to recall selectively self-consistent stimuli than inconsistent ones, and that, on the contrary, some persons would be more likely to favour self-inconsistent stimuli than consistent ones. In the present paper, the former will be referred to as repressers and the latter as sensitizer.

The purpose of the present study was to confirm experimentally the phenomena of selective memory, and to clarify that there would be some correlation between this phenomena and personality variables.

For this purpose, an experiment was designed in which the verbal stimuli were used as memory material and several personality variables were measured.

The obtained data were analyzed by means of a model from " Theory of Digitalization" by Hayashi (1964) which we believe to be a very flexible model as compared to other methods of multivariate analysis. The model employed in this study corresponds to multiple regression analysis. It is true that the application of this model may not reveal the causal relations among variables and the exact process or mechanism between input (independent variables) and output (dependent variable), but it is meaningful and worthwhile for the author to adopt this
TABLE 1

Verbal stimuli used in paired associate learning

\begin{tabular}{lll}
\hline SUNAONA & (obedient) & RENE \\
HOGARAKANA & (cheerful) & RUYO \\
AKARUI & (open) & YUNU \\
ATATAKAI & (warm-hearted) & RAMO \\
SHINSETSUNA & (kind) & REWA \\
SEIJITSUNA & (sincere) & KENE \\
MAJIMENA & (serious) & HOHI \\
NIGIYAKANA & (lively) & YAYU \\
UGHIKINA & (shy) & RUA \\
KACHIKINA & (high-spirited) & TSUHA \\
SHIZUKANA & (sedate) & MUNU \\
MUJYAKINA & (innocent) & SUSE \\
NONKINA & (easy-going) & ROHE \\
OTONASHII & (gentle) & NUMO \\
RIKOTEKINA & (egoistic) & WAHO \\
KOMANNA & (haughty) & IMU \\
IJIWARUNA & (ill-natured) & NANU \\
WAGAMAMANA (willful) & RII \\
INKINA & (sombre) & TEHA \\
TSUMETAI & (cold) & NEME \\
DARASHINAI & (loose) & WANO
\end{tabular}

procedure, because the main purpose of the present study is to provide the fundamental informations in order to construct more precise and specific hypothesis, and to predict the phenomena of selective memory from the combination of personality variables.

\section{MEthod}

Subjects. The $S$ s were 60 undergraduate students, 26 males and 34 females, of Tokyo University of Education, Tokyo University of Liberal Arts and other universities in Tokyo.

Procedure. (A) Measurement of selective memory. First, subjects were required to sort 21 self-descriptive qualifiers into three piles according to the following criteria respectively : (1) the qualifiers which are adequate to represent the subjects' personality, (2) the qualifiers which are opposed to their personality characteristics and (3) the qualifiers which are neutral. The sort was a rectangular distribution with three piles to which 7 cards were assigned respectively.

Then, each subject was presented with the 
pairs of stimuli which consisted of the above mentioned qualifiers and the nonsense syllables selected from the List of Nonassociation Value constructed by Takagi (1960), and was required to learn them (see Table 1). The pairs of stimuli were presented continuously with two second intervals by memory drum. The number of trials was 6 for all subjects.

(B) Measurement of personality and other variables. I. Self-Ideal Discrepancy; The materials used to measure the discrepancy between present self and ideal self was selected from Q-cards devised by the present author and Nagashima previously (1967). The structure of these cards was as follows.

TABle 2

Structure of Q-cards

\begin{tabular}{|c|c|}
\hline $\begin{array}{l}\text { Dependent } \\
\text { variables }\end{array}$ & Levels \\
\hline Ego & $\begin{array}{l}\text { (a) Self-affirmation } \\
\text { (b) Self-denial }\end{array}$ \\
\hline Object & $\begin{array}{l}\text { (c) Mother (d) Friend } \\
\text { (e) Opposite sex }\end{array}$ \\
\hline Attitude & (f) Active (g) Passive \\
\hline
\end{tabular}

II. SEI (Self-Esteem Inventory); It seems that any inventory to measure the degree of self-esteem has not yet been developed in Japan. Therefore, the author devised a tentative inventory in the present study. By this inventory the author intended to measure evaluational and affectional attitude toward self in conscious level.

Sub-categories which were taken into consideration in the process of choosing statements were as follows.

1. the firm belief in one's own ability

2 . self-satisfaction obtained through aggression to others

3. emotionally affirmative attitude toward self

4. positive attitude toward one's own life

5. strong need

6. narcissism

7. rejection of the sympathy of others and avoidance of failure
This inventory was composed of 44 tentative statements. After the test was administered to 100 undergraduate students, good-poor analysis was conducted, and as a result, the number of items was reduced to 23 .

III. Time Orientation; By time orientation the author means the time reference on which the subjects anchor their evaluation or assessment of their self. Time orientation is considered to have some relations with selective memory. However, this variable seems to have not been treated operationally.

In this study, three types of time orientation were set up. They are past-oriented type, present-oriented type and future-oriented type. These three types were defined by means of Semantic Differential scales which were devised by the author. The subjects were asked to rate 21 scales of semantic differential against future, present and past. Factor analysis was applied to these data. Evaluation factor was extracted together with other factors which were neglected because of small amount of factor loadings. 10 qualifiers with high loadings of evaluation were determined. They were used as a measure to define the type.

IV. MMPI, and other variables; The Japanese edition of MMPI published by SankyoBo was used. Also digital-rote-memory (DR-M) was measured. This is not a personality variable but is considered to be related to memory. The stimuli used in measuring this variable were six series of figures. Sex variable was added.

\section{Analytical Procedure}

Adjustment of raw data. Data obtained as the result of associative learning were analyzed into C scores and I scores. The former was the number of responses (in this case, qualifiers) which were previously rated as self-consistent by the subjects, and the latter was the number of the self-inconsistent ones. The object of this treatment was to find out whether a given subject tends to recall consistent qualifiers or inconsistent ones. For this purpose, the data were transformed into the ratio of $\mathrm{C}-\mathrm{I} / \mathrm{C}+\mathrm{I}$ which was referred to as $S$ ratio. This ratio 
TABLE 3

Illustration of categorization

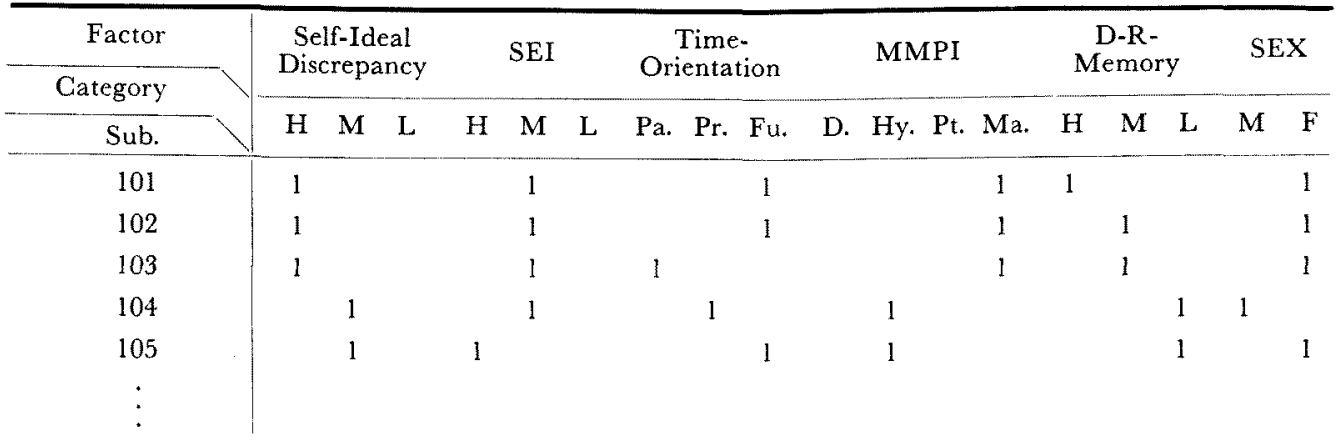

is the outsider (dependent variable) in the present study, that is, the measure of selective memory. $S$ ratio ranges from 1.00 to -1.00 theoretically.

The analytical procedures of the result of personality variables was as follows. First, as to Q-sort, the cross product coefficients of correlation between present and ideal self were calculated. This coefficient is the measure of Self-Ideal Discrepancy.

In the case of SEI (Self-Esteem Inventory), original test scores were used as a measure.

As for the time orientation, the factor scores of past, present and future were obtained respectively by means of SD scale. The $S$ s were classified in to the present-oriented, past-oriented and the future-oriented types respectively according to their factor scores.

In the case of MMPI, only four indice $\mathrm{Hy}$, $\mathrm{D}, \mathrm{Pt}$ and $\mathrm{Ma}$ were taken into consideration in the present study, because the number of categories would have become too many for the analytical model if all the indice of this inventory had been used. These four indice were discovered to have close relation to selective memory by the previous studies (Eriksen, 1954; Truax, 1957).

Finally, the analysis of measurement of digital rote-memory was performed in accordance with the criterion of WISC's scoring method.

Analysis in terms of multiple regression model of "Theory of Digitalization". The purpose of this analytical model was to maxmize the correlation between the measured scores of the outsider obtained by the experiment and the estimated values from the personality variables. To obtain estimated value of each personality factors, it was necessary to determine the number of categories of each variable first. Each subject had to be classified into one of the categories of each variable. The categorization of each sample had to be examined deliberately, because it would influence the efficiency of digitalization. No standardized procedure, however, have been found out (see Yamakawa, 1965). In the present study, the coefficients of correlation between self and ideal-self were categorized into ' high $(\mathbf{H})$ ', ' middle (M)', and 'low (L) ', respectively corresponding to over 0.75 , $0.75-0.40$ and under 0.40 . In SEI, the raw scores over $15.5,15.5-12.5$ and under 12.5 correspond to the categories ' $\mathrm{H}$ ', ' $\mathrm{M}$ ', and ' $L$ '. In D-R-Memory, the categories ' $H$ ', ' $\mathrm{M}$ ', and ' $\mathrm{L}$ ' were assigned to the scores 8 , 7 , and 6 or 0 respectively. Partial result of these categorization is illustrated in Table 3.

\section{Results}

According to the procedure of " Theory of Digitalization ", the author set up the equation in which the values given to the categories of each variable were unknown. A Hipac 3010 computer was used to solve this equation. Category scores in Table 4 are the roots obtained from the equation. Then, this category scores were normalized in such a way that the estimat- 
ed value of outsider might have zero mean and unit variance when the normalized category scores were used in calculation (Table 4).

Every time when a variable was added, corresponding multiple correlation coefficient (MCC) was computed (see Table 5). MCG of all variables showed the value of 0.5460 . This value is an index by which the efficiency of result of analysis

TABLE 4

Category score

\begin{tabular}{|c|c|c|c|}
\hline Factor & Category & $\begin{array}{l}\text { Category } \\
\text { score }\end{array}$ & $\begin{array}{l}\text { Normalized } \\
\text { category } \\
\text { score }\end{array}$ \\
\hline \multirow{3}{*}{$\begin{array}{l}\text { Self-Ideal } \\
\text { Discrepancy }\end{array}$} & $\mathrm{H}$ & -0.1303 & 0.0376 \\
\hline & $\mathrm{M}$ & -0.1470 & 0.0210 \\
\hline & $\mathrm{L}$ & -0.2353 & -0.0674 \\
\hline \multirow{3}{*}{ SEI } & $\mathrm{H}$ & 0 . & -0.0559 \\
\hline & M & 0.1626 & 0.1067 \\
\hline & L & 0.0132 & -0.0427 \\
\hline \multirow{3}{*}{$\begin{array}{l}\text { Time- } \\
\text { Orientation }\end{array}$} & $\mathrm{Pa}$. & 0 . & 0.0127 \\
\hline & Pr. & -0.1185 & -0.1058 \\
\hline & Fu. & 0.0064 & 0.0191 \\
\hline \multirow{4}{*}{ MMPI } & D. & 0 . & -0.1292 \\
\hline & Hy. & 0.0942 & -0.0350 \\
\hline & Pt. & -0.0072 & -0.1364 \\
\hline & Ma. & 0.3027 & 0.1735 \\
\hline \multirow{3}{*}{$\begin{array}{l}\text { D-R- } \\
\text { Memory }\end{array}$} & $\mathrm{H}$ & 0 . & -0.0153 \\
\hline & M & -0.0634 & -0.0787 \\
\hline & L & 0.1042 & 0.0888 \\
\hline \multirow{2}{*}{ SEX } & $\mathbf{M}$ & 0 . & -0.0331 \\
\hline & F & 0.0584 & 0.0253 \\
\hline
\end{tabular}

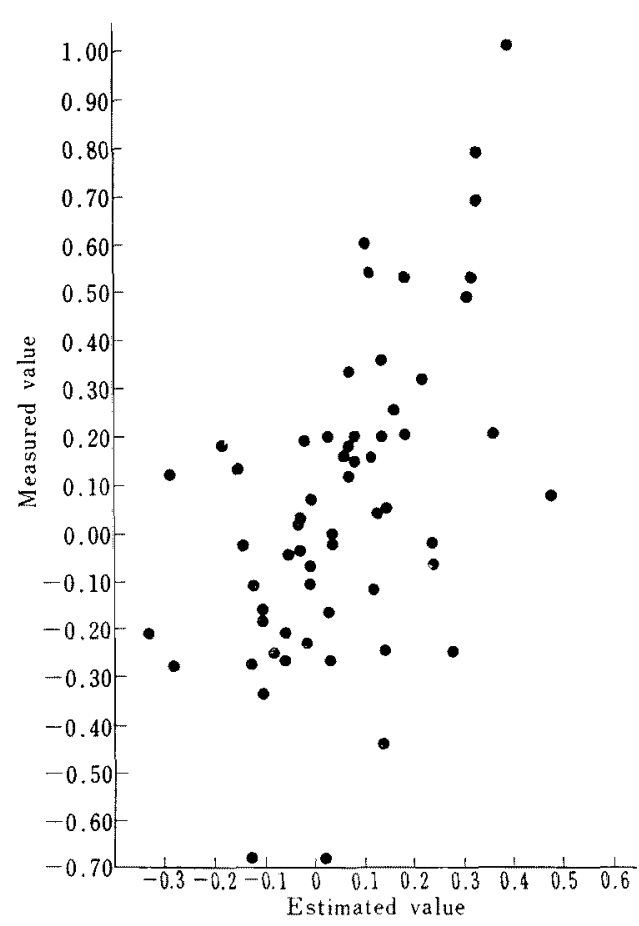

Fig. 1. The regressional relation of the estimated value of outsider to the measured value ( $S$ ratio)

TABLE 5

Analysis by the multiple regression model

\begin{tabular}{lcccc}
\hline & $\begin{array}{c}\text { Multiple } \\
\text { Corre. Coef. }\end{array}$ & $\begin{array}{c}\text { Group par. } \\
\text { Corre. Coef. }\end{array}$ & Range & Rank \\
\hline Self-Ideal Discrepancy & 0.2069 & & 0.1050 & 5 \\
SEI & 0.2803 & 0.0373 & 0.1626 & 3 \\
Time-Orientation & 0.2957 & 0.0097 & 0.1249 & 4 \\
MMPI & 0.4978 & 0.1757 & 0.3099 & 1 \\
D-R-Memory & 0.5402 & 0.0586 & 0.1675 & 2 \\
SEX & 0.5460 & 0.0088 & 0.0584 & 6
\end{tabular}

${ }^{2}$ GPCC of the Sth factor group, $\rho_{a, s}$, is given by

$$
1-\rho_{a_{s}}{ }^{2}, \cdots \cdots=\frac{1-\rho^{2}{ }_{a, 12} \cdots \cdots s}{1-\rho^{2}{ }_{a, 12} \cdots \cdots(s-1)}
$$

Here, $\rho_{a, 12}^{2} \cdots s$ stands for the square of the coef- ficient of multiple correlation when the 1st, 2nd, ..., the $S$ th factors are into consideration.

s Range is computed by taking the difference between the maximum value and minimum one of normalized category scores on each factor. 
is estimated. In Table 5, the group partial correlation coefficients (GPCC) ${ }^{2}$ show the degree of contribution of each variable to the dependent variable, corresponding to range $^{3}$. The most meaningful variable was MMPI, and the least meaningful one was SEX. That is, the values assigned to the categories of SEX were small as compared to the values assigned to other variables. This means that the total MCC would not increase by adding SEX factor.

The partial correlation coefficients (PCG) were computed between each variable and the estimated value of outsider. The result showed that the only one variable of MMPI was statistically significant $(\mathrm{PCC}=0.420, p<0.01)$.

Lastly the regressional relation of the estimated value of outsider to the measured value ( $S$ ratio) is illustrated in Fig. 1.

\section{Discussion}

As stated previously, $S$ ratio $(\mathrm{C}-\mathrm{I} / \mathrm{C}+\mathrm{I})$, which was a measure of selective memory, was used to determine whether a person was a represser or a sensitizer. Persons with positive ratios were considered, by definition, as repressers, and those with negative $S$ ratios as sensitizers. The result of the present experiment showed that, out of sixty subjects, the number of repressers was thirty-one and that of sensitizers was twenty-nine. Thus all subjects were divided into two types. However, no mention was made of the presence of sensitizers in the study conducted by Cartwright. $\mathrm{He}$ asserted that all subjects (especially those who were in maladjusted state) would recall self-consistent stimuli more easily than self-inconsistent ones. The present experiment produced evidence running contrary to his assertion. It may be said that Cartwright's hypothesis is applicable only to specific populations of subjects, but not to other ones, for example, those who have an obsessive trend.

Now the result of multiple regression analysis will be discussed. As mentioned above, the model adopted in this study was different from the general multiple regression analysis. The MCC, the index of efficiency of this analysis, was 0.5460 using all six variables. This value is not large, but is sufficient to enable us to interpret the results. In other words, it is obvious that there is a significant correlation between selective memory and personality variables, although one may not be able to predict completely the measured value of dependent variable from six independent variables. About thirty percent of the total variance can be accounted for by these variables.

In the next paragraph, the degree of the contribution of each variable to selective memory will be discussed in detail.

As to S-I discrepancy, it was found that the factor was not so significant (fifth of six variables). But from the fact that the value given to category ' $\mathrm{H}$ ' or ' $\mathrm{M}$ ' is positive, the subjects who fall in these categories are likely to have high estimated value of outsider. That is, they tend to be related to positive selective memory. This result is analogous to that of the study by Altrocchi, et al. He found that a represser was likely to have a high correlation between self and ideal-self and a sensitizer to have a low correlation.

The contribution of SEI stood third among six factors. The subjects whose self-esteem was extremely high or low were given negative value of category score. This suggests that the subject whose self-esteem deviates from the average tends to be a sensitizer, and that the subject whose self-esteem is ordinary is likely to be a represser.

The weight of time orientation was fourth in order. It was shown that the present-oriented person tends to have a negative selective memory. This result reflects the fact that sensitizers recall obsessively the unpleasant and unacceptable experience of their past and at the same time they have a less optimistic view about 
their future. Therefore, sensitizers tend to be present-oriented. Past or future-oriented persons correspond to repressers.

The present experiment found MMPI to be the most important factor of all six variables. In fact, the $\mathrm{PCC}$ between MMPI and the outsider was 0.420 , which was statistically significant. Sensitizers were more likely to be classified into the categories of D (Depression), Hy (Hysteria) Pt (Psychasthenia). Category D is characterized by lack in self-confidence, constant fear of something, limitation in interest, and introversive behavior. Category $\mathrm{Hy}$ is characterized by constant complaints about their health, overcompensative rejection of the possibility of falling into neuroses, and emphasis on being socialized. Category $\mathrm{Pt}$ is noted for a moderate depressive tendency, mental struggle, lack in self-confidence, lack of concentration of energy, and obsessive behavior. In short, those who have such personality traits as the above mentioned, tend to recall more easily the stimuli which are incongruent to their self-concept.

On the other hand, those who were categorized into Ma (Hypomania) correspond to repressers. These persons are social, enthusiastic, individualistic, impulsive, adventurous, inquisitive, talkative, self-dissatisfied, and so on.

D-R-Memory is not a personality variable, but the experiment revealed that this variable was significantly related to selective memory (second of six variable). This result was not expected by the author, but in a sense is very interesting.

The "pure" mental ability, which was assumed to be measured by D-RMemory test, was considered not to be related to selective memory. But it was actually found to be related to selective memory. This fact must be interpreted in the following way. D-R-Memory test measures not only "pure" mental ability but also other variables such as the psychological set to experimental situation, anxiety for failure, need for achieve- ment, etc. These variables are hypothesized to be the peronality factors which distinguish sensitizers from repressers. Actually, as the data reveal (Table 4), those who gained high score in D-RMemory test tended to be sensitizers and those who gained low scores tended to be repressers. It is assumed that sensitizers would be more highly motivated than repressers to this experimental task. This interpretation must be confirmed by further experimentation.

Finally, the sex variable was found to have no relation to selective memory as the author had expected (sixth of six variable).

In conclusion, it might be said that the experiment supposed the author's hypothesis. It was hypothesized that there would be some individual differences in the course of the learning experiment in which meaningful verbal stimuli were used as material, and that these individual differences could be accounted for by means of personality variables. But it must be recognized that the variables adopted in the present experiment are not completely effective in predicting selective memory because MCC is not sufficiently high (0.5460).

There will be several ways in obtaining a higher degree of efficiency of analysis. One of these is concerned with the number of categories. By increasing the number of categories of each variable, a sufficient amount of information can be utilized. But, in order to increase the number of categories, it is absolutely necessary for the researchers to use a larger sample of subjects. If a small sample is classified into many categories, the number of subjects assigned to a category will be reduced, and as a result, the experimental result will become likely to be influenced by accidental variation of the sample.

Another way concerns the number of personality variables. This might be more essential and effective in nature. The present study was confined to only six factors which the author considered to be 
relevant. But if the number of personality variables is increased, the result will be effective.

In this case, much experimental literature concerning the individual differences in repressive tendency would serve as a good guide. For example, Zeller (1950) and Goldin (1964) presented excellent reviews of experimental studies in which they regarded 'need-achievement ', ' egostrength', etc., as important personality variables. Therefore, the present study might be limited and inexhaustive.

However, the study may act as a pilot one and will contribute very much to the study of emotional factors in memory because it was experimentally confirmed that the phenomena of selective memory could be explained by personality variables, and moreover it was demonstrated that one could treat certain variables simultaneously by the methods of multivariate analysis.

\section{REFERENGES}

Altrocchi, J., Parsons, O.A., \& Dickoff, H. 1960 Changes in self-ideal discrepancy in repressers and sensitizers. $J$. abnorm. soc. Psychol, 61, 67-72.

Cartwright, D.S. 1956 Self-consistency as a factor affecting immediate recall. J. abnorm. soc. Psychol., 52, 212-218.

Eriksen, C. W. 1954 Psychological defenses and ego strength in the recall of completed and incompleted tasks. J. abnorm. sac. Psychol, 49, 45-50.

Goldn, P. C. 1964 Experimental investigation of selective memory and the concept of re- pression and defense: A theoretical synthesis. J. abnorm. soc. Psychol., 69, 365-380.

Gordon, J.R. 1959 The stability of the assumed similarity response set in repressers and sensitizers. J. Pers., 27, 362-373.

Gossett, J. T. 1964 An experimental demonstration of Freudian repression proper. Unpublished doctoral dissertation, Univ. of Arkansas, Fayetteville, Arkansas.

Hayash, C., \& Murayama, T. 1964 The design and practice of marketing research. Tokyo: Nikkankogyo-shinbunsha (in Japanese).

McReynolds, P., \& Ullman, L. P. 1964 Differential recall of pleasant and unpleasant words as a function of anxiety. $J$. clin. Psychol., 20, 79-80.

Rogers, C. R. 1951 Client-centered therapy; its current practices, implications and theory. Boston: Haughton.

Sharp, A. A. 1938 An experimental test of Freud's doctrine of the relation of hedonic tone to memory revival. J. exp. Psychol., 16, 129-137.

TAKAGI, S. (Ed) 1960 The method of psychological research. Tokyo: Iwanami (in Japanese).

Truax, C. B. 1957 The repression response to implied failure as a function of the hysteriapsychasthenia index. $J$. abnorm. soc. Psychol., 55, 188-193.

YAMAKAWA, K. 1965 The discussion about digitalization for the classification of literatures. Mathematical Sciences, 3, 58-62 (in Japanese).

Yamashita, T., \& Nagashima, S. 1967 The study of the relation between recalled-self and adjustment in adolescence. Bull. Clinic. \& Consult. Psychol., 8, (in Japanese with English abstract). (in press)

Zelter, A.F. 1950 An experimental analogue of repression: I. Historical summary. $P_{s y-}$ chol. Bull., 47, 39-51.

(Received July 7, 1967) 